\title{
Vigilância em Saúde no Brasil: Os Desafios dos Riscos Sanitários do Século XXI e a Necessidade de Criação de um Sistema Nacional de VigilânCia em Saúde
}

\author{
HEALTH SURVEILLANCE IN BRAZIL: THE CHALLENGES OF THE \\ SANITARY RISKS IN THE XXI CENTURY AND THE NECESSITY OF A \\ NATIONAL HEALTH SURVEILLANCE SYSTEM
}

\author{
Fernando Aith ${ }^{(*)}$ \\ Sueli Gandolfi Dallari ${ }^{(* *)}$
}

\section{RESUMO}

As evoluções tecnológicas vividas no mundo contemporâneo vêm transformando a sociedade e as relações entre os Estados e as pessoas. A mobilidade do ser humano atingiu níveis nunca antes imaginados, sendo possível chegar de um lado ao outro do mundo em menos de 24 horas. Esta mobilidade também inclui bens e serviços, dando a tônica do mundo globalizado do Século XXI. Neste contexto, os riscos de doenças e outros agravos à saúde se amplificaram intensamente. Hoje, uma epidemia que se inicia na China pode chegar ao Brasil no dia seguinte. O Brasil reconhece a saúde como direito de todos e dever do Estado (CF, art. 196), devendo este organizar-se para a eliminação ou controle dos riscos à saúde que existirem em nossa sociedade. Atualmente, a organização do Estado brasileiro no que se refere à vigilância dos riscos de doenças e outros agravos à saúde é fragmentada, havendo a vigilância sanitária (focada em bens, produtos e serviços), a vigilância epidemiológica (doenças transmissíveis e investigações de outros riscos) e a vigilância ambiental em saúde (meio ambiente em geral, inclusive o do trabalho). Esta fragmentação provoca problemas de gestão e de consolidação de informações estratégicas para a defesa da saúde. Neste sentido, deve-se pensar na organização das vigilâncias dentro de um sistema único e coordenado,

(*) Advogado, mestre em Filosofia e Teoria Geral do Direito pela Universidade de São Paulo (USP), doutor em Saúde Pública pela USP, pesquisador do Centro de Estudos e Pesquisas de Direito Sanitário (CEPEDISA). E-mail: <fernando.aith@ cepedisa.usp.br>

$\left.{ }^{(*}\right)$ Professora Titular da USP e Vice-Presidente do CEPEDISA. E-mail: <sdallari@usp.br>.

Recebido em 20.5.09. Aprovado em 25.6.09. 
denominado Sistema Nacional de Vigilância em Saúde, que articule as diferentes especialidades de vigilância em saúde hoje existentes no Brasil e possibilite um sistema de informações e ações de vigilância em saúde eficaz e resolutivo, capaz de enfrentar a contento situações emergenciais de saúde pública.

\section{Palavras-chave}

Direito à saúde; Direito Sanitário; Vigilância Ambiental; Vigilância em Saúde; Vigilância Epidemiológica; Vigilância Sanitária; Risco Sanitário.

\section{ABSTRACT}

The technological development experienced in the contemporary world are transforming society and relations between State and people. The mobility of human being has reached levels never before imagined and a person can move from one side of the world to the other side in less than 24 hours. This mobility also includes goods and services, giving the keynote of the globalized world of the XXI Century. In this context, the risks of diseases and others health problems are intensely amplified. Nowadays, an epidemic that begins in China can arrive in Brazil the following day. Brazil recognizes health as a universal right and also consider it a State's obligation. Therefore, the State of Brazil is obligated to organize itself to eliminate or control health risks. Today, the organization of the Brazilian State regarding the surveillance of risks of diseases and other health problems is fragmented and includes sanitary surveillance (focused on goods, products and services), epidemiological surveillance (diseases and investigations of other risks) and environmental surveillance in health (the environment in general, including the workplace). This fragmentation causes problems for the management and consolidation of strategic information for health protection. Brazil has the need to think about an other model of organization that put together all "kinds" of surveillances within a single coordinated system, called the National System of Health Surveillance, which would be able to coordinate the various specialties of health surveillance that exists in the country in order to provide a effective system of information and health surveillance, able to face emergency situations of public health.

\section{Keywords}

Control of Diseases; Epidemiological Surveillance; Health Law; Health Surveillance; Right to Health; Sanitary Risk. 


\section{REFLEXÕES INTRODUTÓRIAS: A SAÚDE COMO UM DIREITO HUMANO FUNDAMENTAL NO ESTADO DEMOCRÁTICO DE DIREITO BRASILEIRO}

A atual concepção de Estado modela-se no sentido de direcionar a estrutura estatal para a promoção e proteção dos direitos humanos (civis, políticos, sociais, econômicos, culturais, difusos e coletivos). Estes direitos, por sua vez, exigem, para sua promoção e proteção, um ambiente social dotado de regras de convivência que garantam a todos, sem exceção, o respeito à vida e à dignidade do ser humano. Essas regras devem atingir não só a figura dos governados como também, e principalmente, a figura dos governantes. O exercício do poder deve sujeitar-se a regras preestabelecidas, voltadas à promoção, proteção e garantia dos direitos humanos. A esse conjunto de regras, que tem no seu topo a Constituição e que define o âmbito do poder e o subordina aos direitos e atributos inerentes à dignidade humana, damos o nome de Estado de Direito. ${ }^{(1)}$

As desigualdades sociais verificadas ao longo do século XVIII estimularam o surgimento, ainda no Século XIX, de movimentos pela positivação constitucional dos direitos sociais, pelo reconhecimento expresso de que todos os homens têm direito a condições dignas de vida. O Estado, tal como estava sendo utilizado em seu início, havia se tornado um instrumento de opressão dos trabalhadores e das classes menos favorecidas. Os movimentos do século XIX questionavam a questão da liberdade como sendo um direito apenas destinado ao burguês, já que somente quem tinha tempo e recursos poderia usufruir de fato da tão proclamada liberdade. Os direitos individuais conquistados consagrados a partir da Revolução Francesa estavam se mostrando direitos meramente formais, existentes para uma pequena parcela privilegiada da população.

A proteção exclusiva dos direitos individuais não estava contemplando os princípios da Revolução de 1789, uma vez que haviam sido deixadas de lado a igualdade e a fraternidade. Caberia ao Estado, desta forma, interferir na atividade dos particulares para que estes usufruíssem a liberdade individual sem que com isso prejudicassem os direitos sociais e a busca pela igualdade. Neste mesmo sentido já acenava a Igreja Católica, por intermédio do Papa Leão XIII que, em 1891, redigiu a encíclica Rerum Novarum, na qual advogava a intervenção ativa do estado em questões sociais, visando meIhorar as condições de vida dos miseráveis e excluídos.

Entretanto, somente no século XX os direitos sociais começaram a se incorporar nas constituições dos Estados. A primeira a incluí-los foi a Constituição Mexicana, em 1917, sendo seguida por diversas outras nações, in-

(1) NIKEN, Pedro. El concepto de derechos humanos. San José de Costa Rica: Instituto Interamericano de Derechos Humanos, 1994. p. 22. (Série Estudios de Derechos Humanos, t. 1). 
cluindo o Brasil. Esta evolução histórica de constitucionalização dos direitos humanos resultou num modelo estatal adotado pela grande maioria dos países do mundo, onde figuram, desde o início do século, de um lado, os direitos individuais - civis e políticos -, derivados da Bill of Rights e da Declaração dos Direitos do Homem e do Cidadão e, de outro, os direitos sociais, econômicos e culturais, derivados dos movimentos dos trabalhadores ao longo do século XIX e que refletem pretensões do indivíduo perante o Estado - trabalho (greve, salário mínimo, jornada máxima de trabalho, aposentadoria), acesso aos bens históricos e culturais e às ciências, educação, saúde, moradia, lazer, segurança, previdência social, dentre outros.

Nas últimas décadas, pudemos acompanhar o surgimento dos direitos que têm como titular não os indivíduos na sua singularidade, mas grupos humanos, como a família, o povo, a nação ou a própria humanidade ${ }^{(2)}$. Pode-se dizer que compõem ainda esse conjunto de direitos humanos os direitos ao desenvolvimento, à paz, de propriedade sobre o patrimônio comum da humanidade, ao meio ambiente e de comunicação. ${ }^{(3)}$

O Brasil incorporou em sua organização jurídica e social a lógica do Estado de Direito e da democracia. A Constituição de 1988 protege, em seu art. 5o, os direitos individuais e coletivos, afirmando que "todos são iguais perante a lei, sem distinção de qualquer natureza, garantindo-se aos brasileiros e aos estrangeiros residentes no país a inviolabilidade do direito à vida, à liberdade, à igualdade, à segurança e à propriedade".(4) Ao mesmo tempo em que reconhece e protege os direitos individuais civis e políticos, o Estado de Direito brasileiro protege os direitos sociais, ao reconhecer, na Constituição de 1988, que "são direitos sociais a educação, a saúde, o trabaIho, a moradia, o lazer, a segurança, a previdência social, a proteção à maternidade e à infância, a assistência aos desamparados, na forma desta Constituição". (5)

Complementando o arcabouço constitucional de proteção dos direitos humanos, o $\S 2^{\circ}$ do art. $5^{\circ}$ da Constituição dispõe que "os direitos e garantias expressos nesta Constituição não excluem outros decorrentes do regime e dos princípios por ela adotados, ou dos tratados internacionais em que a República Federativa seja parte".

Os direitos humanos, considerados em sua totalidade, são indivisíveis e devem ser tratados em igual escala hierárquica. A I Conferência Mundial

(2) LAFER, Celso. A reconstrução histórica dos direitos humanos. 2. ed. São Paulo: Companhia das Letras, 1998. p. 125-137.

(3) VASAK. Karel. Leçon Inaugurale, sob o título Pour les Droits de l'Homme de la Troisième Génération: Les Droits de Solidarité, ministrada em 2 de julho de 1979, no Instituto Internacional dos Direitos do Homem, em Estrasburgo, apud BONAVIDES, Paulo. Curso de direito constitucional. 9. ed. São Paulo: Malheiros Ed., 2000. p. 523

(4) BRASIL. Constituição da República Federativa do Brasil (1988). Art. 5º, caput.

(5) BRASIL. Constituição da República Federativa do Brasil (1988). Art. 6o․ 
de Direitos Humanos, realizada em Teerã no ano de 1968, proclamou a indivisibilidade dos direitos humanos, afirmando que a realização plena dos direitos civis e políticos seria impossível sem o gozo dos direitos econômicos, sociais e culturais. Em suma, "entre as duas 'categorias' de direitos individuais e sociais ou coletivos - não pode haver senão complementaridade e interação, e não compartimentalização e antinomia"(6). A proteção internacional dos direitos humanos testemunhou, nas últimas décadas, tentativas ou propostas de categorizações de direitos, dentre as quais a mais próxima da operação dos meios de implementação tem sido precisamente a da suposta distinção entre direitos civis e políticos, e direitos econômicos, sociais e culturais $^{(7)}$. Não tardou muito para que se percebesse que, assim como há direitos civis e políticos que requerem ação positiva do Estado (e. g. Direito Civil à assistência judiciária como integrante das garantias do devido processo legal), também há os direitos econômicos, sociais e culturais ligados à garantia do exercício de medida de liberdade (e. g. direito à greve e liberdade sindical), ao que há que se acrescentar a vinculação dos direitos humanos à garantia efetiva da liberdade da pessoa humana. Ao recordar, a esse respeito, que o núcleo de direitos humanos possui caráter inderrogável (e. g. direitos à vida, a não ser submetido à tortura ou escravidão), encontrando-se inelutavelmente ligado à salvaguarda da própria existência, liberdade e dignidade da pessoa humana, compreende-se a razão para que, no transcurso das três últimas décadas, tenha havido uma reconsideração geral da dicotomia entre os direitos econômicos, sociais e culturais e os direitos civis e políticos. ${ }^{(8)}$

(6) TRINDADE, Antonio Augusto Cançado. Tratado de direito internacional dos direitos humanos, Volume I, Sergio Antonio Fabris Editor, Porto Alegre, Brasil, 1997 p. 360 . A Conferência Mundial de Direitos Humanos de 1993, realizada em Viena, também proclamou solenemente a indivisibilidade entre os direitos individuais, civis, políticos, econômicos, culturais e sociais, estipulando ainda outros princípios de interação, nos seguintes termos: "Todos os direitos humanos são universais, indivisíveis, interdependentes e inter-relacionados.".

(7) A evolução histórica do Direito apresenta também um importante fator de internacionalização do Direito, revigorado principalmente a partir da segunda metade do século XX, após as atrocidades cometidas na Segunda Guerra Mundial. Assim, além da proteção dos direitos humanos positivada nos ordenamentos jurídicos internos das nações soberanas, consagrada nas constituições dos Estados Modernos, existe um sistema de proteção universal dos direitos de todos os seres humanos do mundo, calcada em diversos instrumentos normativos internacionais. Esses instrumentos representam um grande marco na defesa concreta dos direitos humanos, inclusive o direito à saúde, mas certamente a proteção internacional dos direitos humanos ainda tem muito a evoluir. Entre os textos internacionais importantes nesse processo de afirmação internacional dos direitos humanos cumpre destacar, nesse momento, aqueles que, entendemos, formam os pilares do direito internacional moderno, em especial no que guarda relação com o direito sanitário, quais sejam: a Carta das Nações Unidas; a Declaração Universal dos Direitos Humanos; o Pacto dos Direitos Civis e Políticos; o Pacto dos Direitos Econômicos, Sociais e Culturais; a criação da Organização Mundial de Saúde; a Carta da Organização dos Estados Americanos; e a criação da Organização Pan-americana de Saúde. Cada um desses textos internacionais apresenta elementos importantes para a defesa do direito à saúde no campo internacional. Aprofundaremos o seu conteúdo quando tratarmos das fontes do direito sanitário.

(8) TRINDADE, Antonio Augusto Cançado. op. cit., p. 359-360. 
Existem, portanto, no Estado de Direito brasileiro, direitos fundamentais (pois positivados constitucionalmente) que devem ser promovidos e protegidos pela sociedade como um todo e, principalmente, pelos órgãos de Administração do Estado criados pela própria Constituição.

A saúde foi reconhecida, nesse contexto, como um direito humano social, expressamente previsto pela Constituição Brasileira (arts. 6o e 196) e por diversos instrumentos normativos internacionais - notadamente a Declaração Universal de Direitos Humanos e o Pacto dos Direitos Econômicos, Sociais e Culturais. O reconhecimento da saúde como um direito humano fundamental deu origem a uma profusão de normas e decisões jurídicas que têm o escopo de garantir esse importante direito, dando vida e conteúdo a uma parte específica da ciência jurídica, que chamamos de direito sanitário.

Desde a Constituição Federal, passando por normas definidas em tratados internacionais, em leis internas brasileiras e em normas infralegais, encontraremos diversos instrumentos jurídico-normativos que tratam de variados aspectos relacionados com o direito à saúde, sempre voltados a garantir o direito à saúde de cada indivíduo e da sociedade. Esse aparato normativo dá origem à necessidade de uma interpretação sistêmica e lógica, bem como exige das autoridades públicas um dever de agir que se concretiza mediante decisões (a execução de uma política pública, a normatização de um setor da saúde, uma decisão judicial visando garantir um tratamento etc.).

O direito à saúde, reconhecido como um direito humano fundamental, encontra-se categorizado no que se convencionou chamar de direitos sociais ou direitos humanos de segunda geração. A própria Constituição de 1988 expressamente declara a saúde como um direito social (CF, art. 6ㅇ). Entretanto, cumpre destacar, na linha já traçada por Cançado Trindade, que o direito à saúde, como direito social que é, realmente possui a característica de exigir do Estado brasileiro ações concretas e efetivas para a promoção, proteção e recuperação da saúde. Deve assim o Estado intervir na dinâmica social para a proteção do direito à saúde. De outro lado, a saúde também possui diversas características que lhe oferecem contornos de direito subjetivo público. O direito à saúde pode ser também considerado como um direito subjetivo público (faculdade de agir por parte de um cidadão ou de uma coletividade para ver um direito seu ser observado) na medida em que permite que o cidadão ingresse com uma ação junto ao Poder Judiciário para exigir do Estado ou de terceiros responsáveis legalmente a adoção ou a abstenção de medidas concretas em favor da saúde.

Assim, podemos perceber que, como direito social, o direito à saúde exige do Estado a adoção de ações concretas para sua promoção, proteção e recuperação, como a construção de hospitais, a adoção de programas de vacinação, a contratação de médicos etc. Assim, podemos perceber que, como direito social, o direito à saúde exige do Estado a adoção de ações 
concretas para sua promoção, proteção e recuperação, como a construção de hospitais, a adoção de programas de vacinação, a contratação de médicos etc. De outro lado, deve-se ter em vista que o direito à saúde também se configura em um direito subjetivo público, ou seja, um direito oponível ao Estado por meio de ação judicial, pois, permite que um cidadão ou uma coletividade exijam do Estado o fornecimento de um medicamento específico ou de um tratamento cirúrgico, ou, ainda, exijam que o Estado se abstenha de adotar ações que possam causar prejuízos à saúde individual ou coletiva (como, por exemplo, não poluir o ambiente). Assim, o direito à saúde é ao mesmo tempo um direito social e um direito subjetivo público.

O direito à saúde é, portanto, um direito humano fundamental da sociedade brasileira necessário para o desenvolvimento do país. Por essa razão, as ações e serviços de saúde são, no Brasil, considerados como de relevância pública (CF, art. 197) e devem estar sujeitos aos mecanismos de controle social de uma democracia, para evitar eventuais abusos a esse direito.

\section{RISCO SANITÁRIO E VIGILÂNCIA EM SAÚDE}

Como dispõe a Constituição Federal em seu art. 196, um dos deveres do Estado para a garantia do direito à saúde é a redução dos riscos de doenças e outros agravos à saúde. Trata-se de tarefa de extrema complexidade, já que a própria noção do risco, ou especificamente do risco sanitário, depende de uma série de variáveis, destacando-se as variáveis econômicas, culturais, sociais, morais e políticas.

Além disso, já se verificou que o controle das causas do risco torna-se tão improvável que a própria noção de risco é, às vezes, suplantada por outras expressões, que deixam claro o grande conflito subjacente à contemporaneidade, traduzido no ultraindividualismo da sociedade absolutamente interdependente: estilo de vida, escolhas pessoais, responsabilidade, prudência etc. Denis Duclos $^{(9)}$ apresenta uma explicação absolutamente adequada para que se possa compreender porque somente agora a humanidade despertou para perceber a implicação da ciência nas catástrofes ditas naturais. Ele constatou que durante longo tempo houve uma disjunção entre a ciência da descoberta e a ciência do diagnóstico, chamada perícia. Assim, não se questionavam as falhas de uma técnica insuficiente e mais - o que foi mais importante para manter oculto o envolvimento da ciência nas catástrofes não se comentavam os erros ou os comportamentos aventurosos do desenvolvimento científico. E exemplifica tal comportamento com o mapa da disse-

(9) DUCLOS, D. Puissance et faiblesse du concept de risque. L'Année Sociologique, v. 46, n. 2, p. 309-337, 1996. 
minação das doenças infecciosas na África, que recobre quase exatamente aquele da luta contra a varíola. Havia, certamente, um temor reverencial com relação à instituição científica, base de toda a modernidade e da prosperidade que lhe foi associada.

Exatamente porque, no começo do Século XXI, a humanidade sabe que não consegue controlar o risco dito "tecnológico", assiste-se ao retorno agressivo do julgamento moral ou disciplinar. Procura-se trabalhar na avaliação da gravidade de um evento nefasto muito bem identificado e os debates sociais enfatizam os aspectos individuais. É necessário perceber, contudo, que o que se esconde efetivamente atrás do risco tecnológico é a enorme divisão do trabalho social, que corrompe a base de solidariedade orgânica que vinha sendo construída na modernidade. Com efeito, como mostra Comparato, o humanismo solidário resistiu à primeira globalização capitalista, com Locke, Rousseau, Kant, Hegel e, sobretudo, Marx, reafirmando que todos os homens têm dignidade, que a pessoa humana é uma finalidade em si mesma e desnudando a moral burguesa que "reduz a vida social a uma pura e simples defesa do interesse particular"(10). Assim, apesar de o solidarismo não ter sido implementado como opção política, a ideia de solidariedade transformou o direito público positivo, sendo suas principais consequências jurídicas a adoção de um sistema de assistência e de previdência social e a implementação de uma política de socialização dos riscos. Esse direito público definiu uma fase histórica da vida sociopolítica e econômica em que o Estado, por meio de leis, decretos e por convenções coletivas, sob pressão das lutas operárias, se dedica a humanizar os rigores do capitalismo primitivo(11).

Ora, existe, na atualidade, uma crise do paradigma assegurador no Estado-providência, pois, ao assumir a socialização dos riscos por meio do seguro, a sociedade torna secundária a avaliação das faltas pessoais e das atitudes individuais. A seguridade instaura a ideia de uma justiça puramente contratual (o regime de indenizações) deixando de ser necessário o recurso à argumentação jurídica ou moral para fundamentar as políticas sociais. Assim, "o seguro social funciona como a mão invisível produzindo segurança e solidariedade sem que intervenha a boa vontade dos homens"(12). A mesma inadequação revelada pelo mecanismo assegurador na sociedade atual parece caracterizar a ordem jurídica que, para atender a demanda de regulação de sujeitos complexos e de setores de funcionamento autônomo, sobrecarrega o legislador.

De um lado, as normas de prevenção definidas pelo legislador são apenas parcialmente capazes de regular normativamente e incluir no processo democrático os programas de ação complexos, concebidos

(10) COMPARATO, F. K. p. 434.

(11) ALBERT, M. Capitalisme contre capitalisme. Paris: Seuil, 1991.

(12) ROSANVALON, P. La nouvelle question sociale. Paris: Seuil, 1995. 
em função de um futuro longínquo e de prognósticos incertos, que requerem uma constante auto-correção e são de fato dinâmicos. De outro lado, constata-se a derrota dos meios de regulação imperativos de prevenção clássicos, concebidos mais em função dos riscos materiais do que de riscos atingindo potencialmente um número importante de pessoas. ${ }^{(13)}$

Acrescente-se, ainda, que os direitos sociais concebidos como direitos compensadores de uma disfunção passageira são inadaptados e terminam por originar uma espiral de autodestruição da solidariedade.

É preciso, então, repensar a solidariedade, buscando encontrar um caminho comum entre as preferências individuais e as escalas de valores, num contexto de incertezas científicas e do risco da ocorrência de danos graves e irreversíveis. Forma-se o princípio de precaução, reivindicado por segmentos sociais até então afastados por posições ideológicas, econômicas e culturais que pareciam inconciliáveis. Quer-se, ao mesmo tempo, preservar os benefícios resultantes do desenvolvimento científico e agir de modo a garantir a precaução no domínio da saúde pública e do ambiente ${ }^{(14)}$. A constatação de que o risco coletivo é de determinação cultural, recíproca e pública gerou, inclusive, a necessidade de uma nova teoria da justiça para dar forma política aos riscos sociais ${ }^{(15)}$. Ela provocou, igualmente, o desenvolvimento de uma filosofia da precaução(16), construída a partir de uma história da prudência. Afirma Ewald que o paradigma da responsabilidade foi substituído - na passagem para o Século XX - pelo da solidariedade, e que este foi, agora, suplantado pelo da segurança.

A teoria, que começa a ser construída, sobre o princípio de precaução procura minimizar o argumento de que ele conduza à abstenção e, portanto, à estagnação do desenvolvimento científico. Afirma-se que ele implica a radicalização da democracia: exige-se o direito de participar - possuindo todas as informações necessárias e indispensáveis - das grandes decisões públicas ou privadas que possam afetar a segurança das pessoas. A aplicação do princípio de precaução impõe uma obrigação de vigilância, tanto para preparar a decisão, como para acompanhar suas consequências. $\mathrm{E}$, sobretudo, ela promove a responsabilidade política em seu grau mais elevado, uma vez que obriga a avaliação competente dos impactos econômicos e sociais decorrentes da decisão de agir ou se abster.

(13) HABERMAS, J. Droit et démocratie: entre faits et normes. Paris: Gallimar, 1996.

(14) Com esse objetivo o Primeiro-Ministro francês encomendou aos professores Geneviève Viney e Philippe Kourilsky um estudo para definir a posição da França no quadro das discussões sobre a aplicação do princípio de precaução no seio da Organização Mundial do Comércio.

(15) WORMS, F. Risques communs, protection publique et sentiment de justice. L'Année Sociologique, v. 46, n. 2 , p. 287-307, 1996.

(16) François Ewald, um dos mais respeitados autores da teoria do risco, vem trabalhando no tema nos últimos anos. Entre seus artigos, pode-se citar: Philosophie de la précaution. L'Année Sociologique, Sociologique, v. 46, n. 2, p. 382-307, 1996. 
Talvez a maior contribuição trazida pelo princípio da precaução seja, contudo, duplamente jurídica. Com efeito, ao deixar claro que se trata de analisar um risco, isto é, a possibilidade de causar dano a alguém, ainda que sem culpa, a exigência de precaução obriga a tomar em conta, seriamente, a instituição da perícia judicial, mas, também, extrajudicial. É conveniente observar que o risco está diretamente ligado à técnica, não ao indivíduo que dela se vale. A complexidade dos saberes envolvidos na decisão de instituir a vacinação generalizada contra uma grave infecção viral de incidência crescente, ou de retirar do mercado um produto suspeito de causar infecção e morte, com base apenas em informações epidemiológicas ainda não comprovadas laboratorialmente, por exemplo, requer a participação de peritos que não devem ser responsáveis pela decisão, mas de quem se exige o domínio sobre sua área de especialidade e que deverão responder - social e juridicamente - pelas informações prestadas. E, em caso de se exigir a resposta judicial, o juiz deverá ser capaz de formar seu convencimento a partir da apreciação de relatórios periciais que traduzam a complexidade da pesquisa científica em informações que sejam compreensíveis para todos os interessados. É necessário, portanto, que os pesquisadores dominem, também, as ciências sociais - na teoria e na prática - para serem capazes de comunicar à sociedade os resultados de seus experimentos. Do mesmo modo, é preciso que as pessoas em geral conheçam as bases do trabalho científico para poderem escolher o grau de risco ao qual consideram aceitável submeterem-se em nome do progresso.

Enfim, como ensina Comparato, no terceiro milênio é absolutamente indispensável compatibilizar o saber tecnológico à ética. É preciso reconhecer tanto o papel insubstituível da tecnologia no processo evolutivo da espécie humana quanto que ela, "divorciada da ética, conduz à inevitável fratura da humanidade"(17). Assim, o equilíbrio ideal entre o aumento da proteção contra uma doença e a proteção da intimidade e da vida privada, por exemplo, apenas será alcançado quando todos tiverem consciência de que a percepção dos riscos e sua origem são sociais. É necessária, então, uma ética formal remontando à origem dos princípios reguladores da sociedade: a igualdade essencial dos partícipes, sua liberdade e a cooperação entre eles. Esse mesmo acordo racional e razoável que fundamenta os valores políticos deve ser invocado para justificar a implementação da proteção pública a ser exercida contra os riscos comuns. Assim, é preciso encontrar na própria vida moral a fonte conjunta dos riscos sociais e da proteção pública.

(17) COMPARATO, Fabio Konder. A afirmação histórica dos direitos humanos. 1. ed, São Paulo: Saraiva, 1999. p. 435. 


\section{O PRINCÍPIO DA SEGURANÇA SANITÁRIA E A VIGILÂNCIA EM SAÚDE NO ESTADO DEMOCRÁTICO DE DIREITO BRASILEIRO}

No Estado Democrático de Direito Brasileiro, o direito sanitário vem crescendo de forma extremamente rápida, justamente para responder às recorrentes demandas da sociedade pela redução ou eliminação dos riscos à saúde. $\mathrm{O}$ conjunto normativo constitucional e legal que reconhece a saúde como direito fundamental e que estipula as diferentes responsabilidades pela garantia deste direito apresenta, em seu conteúdo, o princípio da segurança sanitária, princípio jurídico de extrema relevância ordenadora de todo o direito sanitário brasileiro.

O princípio da segurança sanitária foi consagrado pela Constituição de 1988, que em seu art. 200, ao estabelecer as competências do Sistema Único de Saúde, listou diversas atribuições relacionadas diretamente com a segurança sanitária. Embora não esteja expressamente previsto com essa terminologia, podemos afirmar que o princípio da segurança sanitária foi reconhecido pela Constituição Federal seja por meio da recorrente menção do dever do Estado de desenvolver políticas preventivas de saúde (arts. 196, 197, 198, II e 200) seja pelo fato que, entre as atribuições expressamente previstas pela Constituição para o SUS, verificamos um enfoque bastante significativo às competências de controle, fiscalização, vigilância e prevenção.

A Constituição Federal orienta o Estado brasileiro a se organizar para a proteção da saúde, sendo que as ações específicas voltadas à garantia de segurança sanitária são exercidas majoritariamente pelo campo denominado vigilância em saúde, ou seja, pelo conjunto de ações de vigilância estatal que garanta o respeito dos governos e da sociedade às normas sanitárias existentes.

A lista de competências do SUS prevista pelo art. 200 da CF é aberta, ou seja, não esgota as suas atribuições, que são mais bem detalhadas na legislação complementar. O que importa ressaltar é que todas as competências constitucionais do SUS expressas no art. 200 são relacionadas com a segurança sanitária, ou seja, visam orientar o SUS para as atividades necessárias à redução de riscos em saúde. Podemos afirmar, assim, que a CF cuidou de definir as bases para que o Brasil organize uma política de segurança sanitária baseada na gestão eficaz dos riscos existentes na sociedade, apoiada em alguns polos essenciais: a segurança sanitária ligada aos tratamentos de saúde; a segurança alimentar; a segurança de produtos e serviços oferecidos para o consumo humano; a segurança contra os efeitos da poluição ambiental; e a segurança contra as atividades humanas potencialmente nocivas à saúde e ao meio ambiente equilibrado(18).

(18) Nesse sentido, DURAND, Christelle. A segurança sanitária num mundo global: aspectos legais e o sistema de segurança sanitária na França. Revista de Direito Sanitário, São Paulo, v. 2, n. 1, p. 59-78, mar. 2001. Diz a autora: "Uma segurança sanitária coerente apoia-se na organização da gestão de riscos ao redor de três polos essenciais: a segurança sanitária ligada aos tratamentos, a segurança alimentar e a proteção da saúde contra os efeitos da poluição". 
Embora o comportamento individual e coletivo seja importante para a redução dos riscos à saúde, é o Estado quem efetivamente assume um papel fundamental para a adoção de todas as medidas possíveis e necessárias para evitar a existência, no ambiente social, de riscos de doenças e de outros agravos à saúde da população. Quando não for possível evitar a existência dos riscos, compete ao Estado adotar as medidas cabíveis para reduzir os efeitos que podem por ser causados pela sua existência. A segurança sanitária, neste sentido, torna-se um princípio constitucional do direito sanitário brasileiro e constitui um dos seus principais alicerces. O direito sanitário organiza a ação de vigilância estatal em busca da segurança sanitária, bem como estabelece normas de conduta para que diversas atividades humanas passem a ser desenvolvidas de forma segura.

O princípio da segurança sanitária, encampado pelo direito, passa a ser um elemento diretivo de todas as atividades humanas de interesse à saúde, exigindo, para sua efetivação, a organização de um sistema de vigilância estatal permanente e eficaz capaz de informar aos gestores públicos responsáveis pelas políticas de saúde sobre a existência de riscos à saúde. Somente um sistema de vigilância eficaz pode orientar o gestor da política de saúde para a adoção das medidas específicas, concretas, necessárias para a redução ou eliminação dos riscos identificados.

No campo da vigilância em saúde, também deve ser considerada a necessidade de vigilância sobre os riscos ambientais, atmosféricos, vetoriais e outros que, tenham ou não a ver com a atividade humana especificamente, podem resultar em graves danos à saúde individual e coletiva. Trata-se de vigilância calcada na precaução sobre riscos incertos e desconhecidos que podem aparecer em decorrência das características que cercam a vida do ser humano no globo terrestre (um novo vírus, um terremoto, uma enchente).

A segurança sanitária também é garantida por políticas multissetoriais que lidam com alguns dos fatores determinantes da saúde ${ }^{(19)}$, responsáveis por resolverem questões associadas ao saneamento básico, meio ambiente, habitação, transporte, entre outras. A proteção da saúde exige uma vigilância cada vez mais forte sobre a poluição existente nos rios, sobre a poluição do meio ambiente urbano ou rural, sobre a poluição sonora, visual, enfim, a proteção da saúde exige que se evite ao máximo a degradação das características físicas ou químicas dos ecossistemas e o direito sanitário contribui sobremaneira nesse sentido.

(19) A Lei n. 8.080/1990 dispõe em seu art. 3o: "A saúde tem como fatores determinantes e condicionantes, entre outros, a alimentação, a moradia, o saneamento básico, o meio ambiente, o trabalho, a renda, a educação, o transporte, o lazer e o acesso aos bens e serviços essenciais; os níveis de saúde da população expressam a organização social e econômica do País. Parágrafo único. Dizem respeito também à saúde as ações que, por força do disposto no artigo anterior, se destinam a garantir às pessoas e à coletividade condições de bem-estar físico, mental e social". 
O princípio da segurança sanitária exige do direito sanitário uma atualização permanente, especialmente em decorrência do constante aparecimento de riscos até então desconhecidos, ou do agravamento dos riscos já conhecidos. Seja em decorrência de uma grande crise (uma grande epidemia, transfusões de sangue contaminado, mortes ou danos por medicamentos falsos etc.), seja em decorrência de um futuro incerto (alimentos transgênicos, engenharia genética) o Direito precisa dar à sociedade uma resposta adequada e funcional para temas fundamentais que a afligem e que podem representar grave risco social. Como bem diagnostica Durand, "se a legislação evolui graças às crises e se as crises permanecem inevitáveis, é invevitável também que o direito progrida e com ele a gestão dos riscos sanitários". (20)

O direito sanitário deve evoluir a fim de dotar o Estado e a sociedade dos instrumentos necessários para aumentar ao máximo a segurança sanitária, por meio da vigilância em saúde. O princípio da segurança sanitária direciona o Estado e a sociedade para que seja organizado um sistema de vigilância em saúde focado na identificação, controle e eliminação de riscos à saúde. Inclui-se, portanto, na atividade de vigilância em saúde, todas as ações e serviços voltados à: identificação dos riscos de doenças e outros agravos à saúde; avaliação dos riscos identificados; adoção de medidas de prevenção e controle; combate aos riscos conhecidos; adoção de medidas que ampliem o conhecimento sobre os eventuais riscos à saúde que possam existir nas diversas atividades humanas ou na natureza; adoção de medidas de proteção coletiva sempre que necessário e de forma prioritária e oferecimento à sociedade de informações claras e precisas sobre os comportamentos mais adequados para a redução dos riscos à saúde.

\section{A ATUAL ORGANIZAÇÃO JURÍDICA E ADMINISTRATIVA DA VIGILÂNCIA EM SAÚDE NO BRASIL}

A garantia da segurança sanitária dá-se por meio da formação de um serviço estatal de vigilância em saúde capaz de organizar de forma sistêmica e coordenada as informações sobre os riscos de doenças e outros agravos existentes no Brasil, processar estas informações com rapidez e adotar as medidas de prevenção e contenção necessárias para a eliminação ou controle dos riscos identificados.

Como mecanismo de garantia da segurança sanitária, a Constituição dispõe que compete ao SUS, inicialmente, adotar políticas públicas que visem à redução do risco de doença e de outros agravos (art. 196). Para tanto, a Constituição atribui ao SUS as competências de "controlar e fiscalizar procedimentos, produtos e substâncias de interesses para a saúde" (art. 200,I),

(20) DURAND, Christelle. op. cit., p. 68. 
"executar as ações de vigilância sanitária e epidemiológica" (art. 200, II) e "colaborar na proteção do meio ambiente, nele compreendido o do trabaIho". Essas competências expressamente previstas pela CF visam garantir que o Estado desenvolva ações de identificação, controle e fiscalização dos riscos à saúde, estejam eles no meio ambiente, nas atividades humanas ou onde estiverem.

A vigilância em saúde, por ter seu foco no risco, exige uma visão global que considere a possibilidade do risco estar em qualquer lugar e apresentar-se das mais diversas formas. Englobam-se, portanto, no âmbito de competências da vigilância em saúde, a vigilância das mais diversas atividades humanas, tais como os atos médicos (clínicos, cirúrgicos, terapêuticos etc.); os movimentos populacionais de fronteiras; a produção, comercialização, dispensação e consumo de medicamentos; o meio ambiente do trabalho; o uso de equipamentos de saúde em estabelecimentos de saúde (máquinas, material cirúrgico, materiais descartáveis etc.); o uso de drogas pela população; a violência, enfim, a vigilância sobre todos os fenômenos, ações, procedimentos, produtos e substâncias de interesse à saúde.

Embora, em seu sentido geral, o dever de vigilância em saúde do Estado deva ser compreendido na sua integralidade, tendo em vista a possibilidade do risco ser encontrado em quaisquer atividades ou ambientes, o tratamento legal dado à questão da vigilância em saúde reflete a histórica organização da vigilância sanitária no Brasil, tendo a própria Constituição Federal incorporado a lógica de vigilâncias especializadas em seu texto. Assim é que verificamos no texto constitucional e nas leis que o regulamentam menção à vigilância sanitária, vigilância ambiental, vigilância epidemiológica e vigilância da saúde do trabalhador. Com efeito, a Constituição Federal prevê, em seus dispositivos, a existência da vigilância sanitária (art. 200, I e II), a vigilância epidemiológica (art. 200, II) e a vigilância relacionada ao meio ambiente (art. 200, VIII), aí incluído o meio ambiente do trabalho (Art. 200, II e VIII). A Lei Orgânica da Saúde - LOS (Lei Federal n. 8.080/90), por sua vez, reforçou a existência de setores especializados de vigilância em saúde, dispondo de artigos específicos sobre cada uma das especialidades de vigilância acima referidas.

Os textos normativos que regulam estas diferentes especialidades da vigilância em saúde demonstram as dificuldades conceituais advindas da lógica fragmentada. Fica latente a superposição de competências entre estas diferentes vigilâncias, especialmente quando comparamos as duas mais clássicas, ou seja, a vigilância sanitária e a vigilância epidemiológica.

Com efeito, de acordo com a LOS,

entende-se por vigilância sanitária um conjunto de ações capaz de eliminar, diminuir ou prevenir riscos à saúde e de intervir nos problemas sanitários decorrentes do meio ambiente, da produção e circulação de bens e da prestação de serviços de interesse da saúde" (art. 7ํㅗ §1ํ). 
A vigilância sanitária abrange

o controle de bens de consumo que, direta ou indiretamente, se relacionem com a saúde, compreendidas todas as etapas e processos, da produção ao consumo e o controle da prestação de serviços que se relacionam direta ou indiretamente com a saúde.

A vigilância epidemiológica, em seu conceito legal, apresenta características muito parecidas, senão idênticas. Isto porque a Lei n. 8.080/90 a conceitua como:

um conjunto de ações que proporcionam o conhecimento, a detecção ou prevenção de qualquer mudança nos fatores determinantes e condicionantes de saúde individual ou coletiva, com a finalidade de recomendar e adotar as medidas de prevenção e controle das doenças ou agravos (art. $7^{\circ}$, $\S 2^{\circ}$ ).

Ainda no campo da vigilância epidemiológica, a Lei n. 6.259 de 1975, regulamenta as ações de vigilância epidemiológica no Brasil, dispondo sobre o programa nacional de imunizações, estabelecendo normas relativas à notificação compulsória de doenças e definindo as linhas gerais deste subsistema da vigilância em saúde. De acordo com seus dispositivos, sempre que a autoridade sanitária deparar-se com hipóteses excepcionais de doenças e agravos que ameacem a saúde pública, deverá utilizar-se dos recursos a ela atribuídos pela legislação sanitária em vigor para a proteção da vida e da integridade física e mental da população (art. 12 da Lei n. 6.259/ $\left.1975^{(21)}\right)$. Essa lei dispõe, ainda, que as pessoas físicas e as entidades privadas devem sujeitar-se ao controle determinado pela autoridade sanitária (art. 13 da Lei n. 6.259/1975(22)). Trata-se de uma orientação firme da lei para que a autoridade pública observe o seu dever constitucional de proteção da saúde, especialmente no que se refere à redução de riscos e de doenças e de outros agravos.

Percebe-se que, embora a legislação apresente expressamente os conceitos das vigilâncias especializadas, ao analisarmos os textos normativos que nos oferecem estes conceitos verificamos ampla área de superposição entre as "diferentes" vigilâncias. Assim, se a vigilância sanitária é o "conjunto de ações capaz de eliminar, diminuir ou prevenir riscos à saúde e de intervir nos problemas sanitários decorrentes do meio ambiente" (Lei n. 8.080/1990,

(21) Dispõe o art. 12 da Lei n. 6.259/1975: "Em decorrência dos resultados, parciais ou finais, das investigações, dos inquéritos ou levantamentos epidemiológicos de que tratam o art. 11 e seu parágrafo único, a autoridade sanitária fica obrigada a adotar, prontamente, as medidas indicadas para o controle da doença, no que concerne a indivíduos, grupos populacionais e ambiente".

(22) Dispõe o art. 13 da Lei n. 6.259/1975. As pessoas físicas e as entidades públicas ou privadas, abrangidas pelas medidas referidas no art. 12 , ficam sujeitas ao controle determinado pela autoridade sanitária. 
art. $7^{\circ}, \S 1^{\circ}$ ), certamente a vigilância sanitária incorpora em seu âmbito de ação a prevenção de riscos à saúde existentes nos bens, produtos, serviços e também no meio ambiente.

De outro lado, se vigilância epidemiológica é o "conjunto de ações que proporcionam o conhecimento, a detecção ou prevenção de qualquer mudança nos fatores determinantes e condicionantes de saúde individual ou coletiva, com a finalidade de recomendar e adotar as medidas de prevenção e controle das doenças ou agravos" (Lei n. 8.080/1990, art. $7^{\circ}$, $\S 2^{\circ}$ ), fica evidente que ela também pode incorporar em seu âmbito de atuação a prevenção de riscos à saúde existentes nos bens, produtos, serviços e também no meio ambiente. Afinal, pode-se identificar fatores determinantes e condicionantes de saúde individual e coletiva nos alimentos, nos brinquedos, na água, no ar, na terra, nos estabelecimentos comerciais. Vê-se que ambos os conceitos têm como foco principal a prevenção de riscos à saúde e que ambas as vigilâncias devem adotar medidas de proteção e prevenção contra esses riscos. Vê-se, também, que ambos os conceitos incorporam ações que são, naturalmente, relacionadas à contenção dos riscos ambientais.

Esta lógica jurídica de fragmentação da vigilância em saúde em vigilâncias epidemiológica, sanitária e ambiental acabou se refletindo na organização dos serviços estatais de vigilância em saúde, que passaram a operar por campos de especialidade específicos.

Um dos aspectos práticos verificados em decorrência de tal superposição, e que gera questões importantes, refere-se ao poder de polícia. De fato, o poder de polícia administrativa, típico da atividade de vigilância estatal, está inserido no âmbito da vigilância em saúde como um todo, não sendo particularidade de nenhuma das vigilâncias especializadas. Assim, tanto a vigilância epidemiológica como a sanitária ou a ambiental utilizam o poder de polícia em suas ações. No entanto, quando se verifica a prática das atividades de vigilância em saúde hoje no Brasil, pode-se perceber que há uma certa desarticulação entre os agentes públicos responsáveis pelas diferentes vigilâncias, ocasionando ora duplicidade de ações, ora mobilização desnecessária de agentes públicos e ora omissões graves.

A fragmentação da compreensão e da prática da vigilância em saúde no Brasil e seus reflexos também podem ser verificados no âmbito da organização interna das estruturas administrativas das diferentes unidades federativas brasileiras (União, Estados, Distrito Federal e Municípios). O melhor exemplo desta fragmentação encontra-se na própria organização das ações de vigilância em saúde no âmbito federal.

A Administração direta da União está regulada pela Lei n. 10.683, de 28 de maio de 2003, que "dispõe sobre a organização da Presidência da República e dos Ministérios". O art. 25 lista os Ministérios que compõem a Administração Direta da União, sendo que o Ministério da Saúde figura no 
seu inciso XX. O art. 27 da mesma lei dispõe sobre as áreas de competência dos Ministérios, dispondo sobre o Ministério da Saúde em seu inciso XX nos seguintes termos:

Art. 27. Os Assuntos que constituem áreas de competência de cada Ministério são os seguintes: (...) XX - Ministério da Saúde: a) política nacional de saúde; b) coordenação e fiscalização do Sistema Único de Saúde; c) saúde ambiental e ações de promoção, proteção e recuperação da saúde individual e coletiva, inclusive dos trabalhadores e dos índios; d) informações em saúde; e) insumos críticos para a saúde; f) ação preventiva em geral, vigilância e controle sanitário de fronteiras e de portos marítimos, fluviais e aéreos; g) vigilância de saúde, especialmente quanto às drogas, medicamentos e alimentos; $h$ ) pesquisa científica e tecnologia na área de saúde.

A organização interna de cada Ministério da Administração Federal varia conforme a área de atuação; mas, a todos eles corresponderá uma estrutura básica definida pela Lei n. 10.683/2003. Conforme prevê o seu art. 28, haverá, na estrutura básica de cada Ministério, uma Secretaria Executiva (exceto nos Ministérios da Defesa e das Relações Exteriores), o Gabinete do Ministro e a Consultoria Jurídica (exceto no Ministério da Fazenda, onde é exercida pela Procuradoria-Geral da Fazenda Nacional). A Lei dispõe também sobre os órgãos específicos que integram cada um dos Ministérios, sendo que o inciso $X X$ do art. 29 dispõe que integra a estrutura básica do Ministério da Saúde o Conselho Nacional de Saúde, o Conselho Nacional de Saúde Suplementar e até cinco secretarias.

A organização específica do Ministério da Saúde foi definida pelo Decreto Federal n. 5.974, de 29 de novembro de 2006, que aprova a estrutura regimental e o quadro demonstrativo de cargos em comissão e das funções gratificadas. O Decreto divide o Ministério em órgãos de assistência direta e imediata ao Ministro de Estado, órgãos específicos e singulares, órgãos colegiados e entidades vinculadas. A Secretaria de Vigilância em Saúde SVS ${ }^{(23)}$ é um órgão específico singular do Ministério da Saúde e tem como

(23) Dispõe o art. 31 do Decreto n. 5.974/2006: "À Secretaria de Vigilância em Saúde compete: I — coordenar a gestão do: a) Sistema Nacional de Vigilância Epidemiológica; b) Sistema Nacional de Vigilância Ambiental em Saúde, incluindo ambiente de trabalho; c) Sistema Nacional de Laboratórios de Saúde Pública, nos aspectos pertinentes à vigilância epidemiológica e ambiental em saúde; d) Sistemas de Informação Epidemiológica; e e) Programa Nacional de Imunizações; II — elaborar e divulgar informações e análise de situação da saúde que permitam estabelecer prioridades, monitorar o quadro sanitário do País e avaliar o impacto das ações de prevenção e controle de doenças e agravos, bem como subsidiar a formulação de políticas do Ministério; III — coordenar a execução das atividades relativas à disseminação do uso da metodologia epidemiológica em todos os níveis do SUS para subsidiar a formulação, implementação e avaliação das ações de prevenção e controle de doenças e de outros agravos à saúde; IV - coordenar a execução das atividades relativas à prevenção e ao controle de doenças e outros agravos à saúde; $\mathrm{V}$ - coordenar e supervisionar a execução das atividades técnicas desenvolvidas pelo Instituto Evandro Chagas, 
órgãos departamentais o Departamento de Vigilância Epidemiológica(24) e o Departamento de Análise de Situação de Saúde ${ }^{(25)}$. De acordo com as suas competências definidas no Decreto n. 5.974/2006, compete à SVS coordenar a gestão do Sistema Nacional de Vigilância Epidemilógica, do Sistema Nacional de Vigilância Ambiental em Saúde, do Sistema Nacional de Laboratórios de Saúde Pública, no que se refere à vigilância ambiental e epidemiológica. Vê-se, portanto, que embora o nome da Secretaria seja de Vigilância em Saúde,

pelo Centro de Referência Professor Hélio Fraga e pela Central de Armazenagem e Distribuição de Insumos Estratégicos; VI — coordenar o processo de elaboração e acompanhamento da Programação Pactuada Integrada de Epidemiologia e Controle de Doenças (PPI-ECD); VII — participar da elaboração, implantação e implementação de normas, instrumentos e métodos que fortaleçam a capacidade de gestão do SUS, nos três níveis de governo, na área de epidemiologia, prevenção e controle de doenças; VIII - fomentar e implementar o desenvolvimento de estudos e pesquisas que contribuam para o aperfeiçoamento das ações de vigilância epidemiológica e ambiental em saúde; IX promover o intercâmbio técnico-científico com organismos governamentais e não-governamentais de âmbito nacional e internacional, nas áreas de epidemiologia e controle de doenças; $X$ - propor políticas e ações de educação em saúde pública, referentes às áreas de epidemiologia, prevenção e controle de doenças; XI - prestar assessoria técnica e estabelecer cooperação com Estados, Municípios e o Distrito Federal, visando potencializar a capacidade gerencial e fomentar novas práticas de vigilância e controle de doenças; e XII - formular e propor a Política de Vigilância Sanitária, bem como regular e acompanhar o contrato de gestão da vigilância sanitária."

(24) Dispõe o Art. 32 do Decreto 5.974/2006: "Ao Departamento de Vigilância Epidemiológica compete: I - propor normas relativas a: a) ações de prevenção e controle de doenças transmissíveis; b) notificação de doenças transmissíveis; c) investigação epidemiológica; e d) vigilância epidemiológica, nos postos de entrada do território nacional; II - adotar as medidas de prevenção e controle dos fatores de risco e das doenças ou agravos à saúde, pertinentes ao seu campo de atuação; III coordenar as ações de epidemiologia e controle de doenças e agravos inusitados à saúde, de forma complementar ou suplementar, em caráter excepcional, quando for superada a capacidade de execução dos Estados, houver o envolvimento de mais de um Estado ou riscos de disseminação em nível nacional; IV - normatizar e definir instrumentos técnicos relacionados aos sistemas de informações sobre doenças de notificação compulsória e doenças sob monitoramento; $V$ - analisar, monitorar e orientar a execução das ações de prevenção e controle de doenças que integrem a lista de doenças de notificação compulsória ou que venham assumir importância para a saúde pública; VI — elaborar indicadores de vigilância epidemiológica para análise e monitoramento do comportamento epidemiológico das doenças sob vigilância e agravos inusitados à saúde; VII — propor a lista nacional de doenças de notificação compulsória; VIII - propor o esquema básico de vacinas de caráter obrigatório; IX - coordenar a investigação de surtos e epidemias, em especial de doenças emergentes e de etiologia desconhecida ou não esclarecida, bem como de eventos adversos temporalmente associados à vacinação; $\mathrm{X}$ - normatizar e supervisionar o Sistema Nacional de Laboratórios de Saúde Pública nos aspectos relativos à vigilância epidemiológica e ambiental em saúde; XI — normatizar, coordenar e supervisionar a utilização de imunobiológicos; XII — participar da elaboração e supervisionar a execução das ações na PPI-ECD; e XIII - prestar assessoria técnica e estabelecer cooperação a Estados, Municípios e ao Distrito Federal na organização das ações de epidemiologia, imunização, laboratório e demais ações de prevenção e controle de doenças." (25) Dispõe o art. 33 do Decreto n. 5.974/2006: "Ao Departamento de Análise de Situação de Saúde compete: I - elaborar estudos e análises para monitoramento do quadro epidemiológico e avaliação do impacto das políticas e programas de saúde; II - monitorar o comportamento epidemiológico de doenças não transmissíveis e outros agravos à saúde; III — normatizar e coordenar a execução dos sistemas de estatísticas vitais; IV - promover e divulgar análise das informações geradas pelos sistemas; V - desenvolver metodologias para estudos e análises de situação de saúde; VI — participar da elaboração e supervisionar a execução das ações na PPI-ECD; e VII — prestar assessoria técnica e estabelecer cooperação a Estados, Municípios e ao Distrito Federal na organização das ações inerentes à análise de situação de saúde." 
suas competências referem-se especificamente aos sistemas de vigilância epidemiológica e ambiental, aí inserido o meio ambiente do trabalho.

Verifica-se, assim, que a política de vigilância epidemiológica, parte integrante da vigilância em saúde, é coordenada no âmbito nacional pela Secretaria de Vigilância em Saúde do Ministério da Saúde - SVS/MS. Este órgão trabalha para a promoção e disseminação do uso da metodologia epidemiológica em todos os níveis do SUS, conforme diretriz expressamente prevista pela Lei n. 8.080/1990 (Art. 8º, VII). As ações da SVS têm como objetivo o estabelecimento de sistemas de informação e análises que permitam o monitoramento do quadro sanitário do país e subsidiem a formulação, implementação e avaliação das ações de prevenção e controle de doenças e agravos, a definição de prioridades e a organização dos serviços e das ações de saúde. Nesse sentido, estabelece a lista de doenças de notificação compulsória( ${ }^{(26)}$, as políticas de prevenção de doenças transmissíveis e não transmissíveis, bem como diversos programas nacionais ${ }^{(27)}$ de controle e prevenção de doenças, com destaque para o Programa Nacional de Imunizações ${ }^{(28)}$. Para a execução de certas políticas de vigilância epidemiológica, o Ministério da Saúde conta, ainda, com a Fundação Nacional de Saúde (FUNASA). E compete à Agência Nacional de Vigilância Sanitária (ANVISA) executar as atividades de vigilância epidemiológica e de controle de vetores relativas a portos, aeroportos e fronteiras, sob orientação técnica e normativa do Ministério da Saúde (Lei n. 9.782/99, art. $7^{\circ}, \S 3^{\circ}$ ).

Já a vigilância sanitária, outra parte integrante da vigilância em saúde, encontra-se organizada em apartado da SVS, sendo de competência da ANVISA. Criada pela Lei n. 9.782, de 26 de janeiro de 1999, a Agência tem como finalidade institucional:

promover a proteção da saúde da população, por intermédio do controle sanitário da produção e da comercialização de produtos e serviços submetidos à vigilância sanitária, inclusive dos ambientes, dos processos, dos insumos e das tecnologias a eles relacionados, bem como o controle dos portos, aeroportos e fronteiras (Lei da ANVISA, art. 6\%).

A ANVISA compõe o Sistema Único de Saúde, competindo-lhe coordenar o Sistema Nacional de Vigilância Sanitária.

(26) Portaria GM n. 2.325, de 8 de dezembro de 2003.

(27) O princípio da segurança sanitária é o fundamento de diversos textos normativos do direito sanitário. Vários programas de vigilância epidemiológica são criados e desenvolvidos através do estabelecimento de normas jurídicas, geralmente estabelecidas por Portarias, para que o Estado se organize no sentido de aumentar a segurança sanitária no país. Apenas a título de exemplo, destacamos: Programa Nacional de Controle da Dengue, Programa Nacional de Prevenção e Controle da Malária, Programa Nacional de Eliminação da Hanseníase, Programa Nacional de Controle da Tuberculose, Plano de Intensificação das Ações de Prevenção e Controle da Febre Amarela.

(28) Portaria n. 597, de 8 de abril de 2004, que estabelece o calendário nacional de vacinação. 
Com relação aos Estados, ao Distrito Federal e aos Municípios, a organização de suas vigilâncias em saúde também é regulada por leis específicas, aprovadas no âmbito de cada ente federativo. Em geral seguem a lógica da organização administrativa da Administração Pública Federal e apresentam estrutura semelhante, não havendo grandes distinções com relação à organização da União. O que mudam são algumas terminologias e competências, sendo que, na área da saúde, tanto os Estados como os Municípios podem ter (e geralmente o tem) um órgão específico destinado a desenvolver as ações e serviços públicos de vigilância em saúde, normalmente fragmentado da mesma forma que a União.

A atual estrutura normativa e administrativa do Estado brasileiro ainda não oferece as condições ideais necessárias para cumprir integralmente o seu dever de garantir a saúde da população. Verifica-se, na ordenação jurídica e administrativa, uma fragmentação da noção de vigilância em saúde em várias vigilâncias, fragmentando-se também a própria organização do serviço estatal de vigilância em saúde. Assim, temos vários sistemas de vigilância: o sistema de vigilância epidemiológica, o sistema de vigilância sanitária e o sistema de vigilância ambiental.

Ao determinar que a saúde é um dever do Estado, a ser garantido mediante políticas econômicas ou sociais que visem à redução dos riscos de doenças e de outros agravos à saúde, a Constituição Federal de 1988 quis dizer que compete ao Estado prever os riscos que existem na sociedade e que podem causar doenças ou agravos à saúde e adotar as medidas necessárias para evitá-los ou reduzi-los. Trata-se de uma função eminentemente preventiva do Estado, voltada à segurança sanitária. O Estado deve atuar contra os riscos inerentes à vida em sociedade que guardam relação com a saúde da população, ele deve tomar as medidas cabíveis para reduzir ao máximo os riscos existentes.

Esta organização estatal deve ser feita com respeito aos princípios constitucionais da integralidade dos serviços de saúde, da eficiência administrativa e da participação da comunidade. Certamente que muito se avançou na estruturação dos serviços de vigilância em saúde no país, mas é certo também que ainda existem muitos ajustes a serem feitos.

Para a organização da vigilância em saúde no país, mostra-se conveniente a unificação dos diversos "sistemas de vigilância" existentes em um só sistema de vigilância em saúde, capaz de reunir todas as informações necessárias para a identificação de riscos em saúde, sejam eles riscos da "vigilância sanitária", da "vigilância epidemiológica" ou da "vigilância ambiental". É preciso ainda ampliar a percepção sobre a necessidade de integração dos serviços de vigilância em saúde com os serviços de atenção à saúde, já que os hospitais e postos de saúde são sentinelas importantes na detecção de riscos. 
Para finalizar o presente artigo, apresenta-se a seguir algumas considerações sobre os possíveis caminhos a serem seguidos para o aperfeiçoamento do sistema nacional de vigilância em saúde.

\section{A NECESSIDADE DE CRIAÇÃO E ORGANIZAÇÃO DE UM SISTEMA NACIONAL DE VIGILÂNCIA EM SAÚDE — SINVES}

Como visto, não há no Brasil a consolidação normativa ou administrativa de uma cultura de vigilância em saúde integral, que considere o risco como uma possibilidade que está além de qualquer categorização ou especialização que se queira fazer. Há, isso sim, uma fragmentação na organização dos serviços de vigilância que, muitas vezes, provocam duplicidade de ações ou, pior ainda, vácuos de vigilância.

Mostra-se imperioso o aperfeiçoamento normativo para que se crie um Sistema Nacional de Vigilância em Saúde, sistema este que deve reunir o conjunto de ações e serviços de saúde voltado à detecção e análise de mudanças nos fatores determinantes e condicionantes de saúde individual ou coletiva, com a finalidade de recomendar e adotar as medidas necessárias para a promoção da saúde e à prevenção e controle de riscos, doenças e agravos à saúde.

Este sistema seria o responsável pela organização administrativa da União, dos Estados, do Distrito Federal e dos Municípios no sentido de desenvolverem uma Política Nacional de Vigilância em Saúde e atuarem conjuntamente para a implementação desta política de forma articulada e coordenada.

As ações e serviços que compõem o Sistema de Vigilância em Saúde deverão abranger a coleta e análise de informações para a detecção dos riscos e agravos à saúde e a ampla disseminação da informação analisada; a execução de investigações e levantamentos necessários à programação e à avaliação das medidas de controle de doenças e de situações de agravos ou de risco potencial à saúde detectada no país e o planejamento e a adoção das medidas indicadas para a promoção da saúde e para o controle das doenças e agravos detectados.

Não há necessidade de se criar ou extinguir órgãos atualmente existentes para a constituição do Sistema de Vigilância em Saúde. Basta apenas harmonizar as diversas ações fragmentadas hoje realizadas, criando-se mecanismos legais de articulação das ações e informações. O Sistema de Vigilância em Saúde deverá abranger, assim, de forma harmônica, o conjunto de ações e serviços de saúde voltados à identificação de doenças transmissíveis e não transmissíveis, situações de risco e agravos à saúde e à adoção de medidas efetivas para o controle ou eliminação dos riscos à saúde 
identificados, envolvendo todos os profissionais de saúde, os órgãos que integram o SUS e os estabelecimentos privados de saúde, em todo o território nacional.

Necessário destacar que, no âmbito do Estado Democrático de Direito, todas as ações do Sistema de Vigilância em Saúde deverão se realizar com o máximo respeito à dignidade essencial das pessoas. Todos deverão ser pessoalmente informados das razões que levaram a autoridade sanitária a decretar a medida sanitária limitativa dos seus direitos, sempre que possível e, sempre que não for possível a informação pessoal, as autoridades sanitárias estão obrigadas a utilizar todos os meios de comunicação social a fim de garantir que todas as pessoas possam compreender as razões de adoção das medidas sanitárias. Além disso, a adoção de medidas sanitárias deverá considerar as diferenças culturais, sociais, econômicas e ambientais da região, buscando respeitar, sempre que possível, as culturas, ambientes e realidades locais, inclusive quando se tratar de cadáveres.

Os dados coletados e as informações geradas no SINVES devem respeitar o direito dos indivíduos à intimidade e à privacidade, devendo os responsáveis pela vigilância manter sigilo quanto à identificação pública dos indivíduos que constem nas informações coletadas, salvo nos casos expressamente previstos em lei.

Deve ser conferido ao Ministério da Saúde e aos gestores do Sistema Nacional de Vigilância em Saúde nas demais Unidades federais estabelecer mecanismos que possibilitem a participação da comunidade na elaboração e execução da Política Nacional de Vigilância em Saúde. O processo de planejamento das ações e dos serviços de vigilância em saúde deverá integrar-se aos respectivos planos de saúde e contar, especialmente, com a participação dos Conselhos de Saúde.

Para que as ações e medidas do Sistema sejam sempre democráticas, junto a todas as bases de dados epidemiológicos do SINVES devem funcionar Comissões de Acesso, compostas pelo povo e por cientistas em igual proporção, destinadas a definir as condições e autorizar o acesso às informações constantes daquela base.

Para a garantia da segurança sanitária da população, as direções federal, estaduais e municipais do US deverão dispor do poder de polícia sanitário, entendido como a faculdade que tem a administração pública para, por meio de suas autoridades sanitárias, limitar ou disciplinar direito, interesse ou liberdade, regulando a prática ou abstenção de ato, em razão de interesse público concernente à detecção, prevenção e controle de riscos de doenças e de agravos à saúde. O gestor de saúde da União, dos Estados, do Distrito Federal e dos Municípios deve ser capaz de definir, por Portaria publicada no Diário Oficial, os agentes públicos ou servidores que exercerão a função de autoridade sanitária em seus respectivos territórios, conforme as suas necessidades. 


\section{INSTRUMENTOS POLÍTICOS E ADMINISTRATIVOS NECESSÁRIOS PARA A CONSOLIDAÇÃO DE UM SISTEMA NACIONAL DE VIGILÂNCIA EM SAÚDE - SINVES}

As ações de vigilância em saúde devem ser desenvolvidas por meio de um conjunto de medidas e instrumentos jurídicos, sanitários e administrativos fundamentais para a execução da Política Nacional de Vigilância em Saúde, definida em conjunto pela União, Estados, Distrito Federal e Municípios.

Dentre os instrumentos jurídicos fundamentais para a organização da vigilância em saúde no país, destacam-se: a coleta, o armazenamento e a análise de informações estratégicas em saúde; a gestão nacional das informações estratégicas do sistema de vigilância em saúde; o sistema nacional de laboratórios de saúde pública; as investigações, inquéritos e levantamentos de dados no âmbito do SINVES.

Analisemos cada um destes instrumentos:

\section{Coleta, Armazenamento e Análise das Informações Estratégicas em Saúde}

O Sistema Nacional de Vigilância em Saúde - SINVES deve ser capaz de utilizar informações de qualquer procedência que sejam relevantes para a tomada de decisões pelos gestores públicos, visando à promoção da saúde, à prevenção e ao controle de doenças. O Sistema deve contar, para o desenvolvimento de suas atividades, com os dados e informações coletados em todos os níveis de atuação do sistema de saúde, incluindo os laboratórios e a rede de assistência privada.

Além disso, Sistema deve ser alimentado por alguns dados e informações estratégicos, destacando-se os seguintes: dados demográficos, socioeconômicos e ambientais, visando quantificar a população e gerar informações sobre suas condições de vida, tais como as características de sua distribuição, as condições de saneamento, climáticas, ecológicas, habitacionais e culturais da população, entre outros; dados de morbidade, obtidos mediante a notificação de casos, surtos e epidemias; dados de produção de serviços ambulatoriais e hospitalares, dados de serviços de sentinela, registros de base populacional, dados de investigação epidemiológica, de busca ativa de casos, de cobertura vacinal e de estudos e inquéritos epidemiológicos, entre outras formas; dados de mortalidade, obtidos por meio das declarações de óbitos, entre outras; notificações de quadros mórbidos inusitados e das demais doenças que, pela ocorrência de casos julgada anormal pelo gestor, sejam de interesse para a tomada de medidas de caráter coletivo, tais como os dados de notificação de surtos e epidemias e os dados obtidos por meio da notificação compulsória de doenças. 
Para a obtenção dos dados referidos, o Sistema de Vigilância em Saúde deve ser capaz de utilizar, além dos sistemas de informação em saúde existentes, todos os meios que possibilitem a obtenção de informações relevantes à saúde, tais como publicações científicas, notícias divulgadas na imprensa ou os serviços de atendimento à população. Além disso, qualquer cidadão pode comunicar à autoridade sanitária local a ocorrência de caso de doença transmissível ou de agravos à saúde que possam representar risco à sociedade, devendo a autoridade sanitária responsável, no âmbito do SINVES, pela coleta e análise das informações em saúde, estabelecer e divulgar procedimentos de comunicação e notificação compulsória, visando o controle dos riscos identificados.

\section{A Gestão Nacional das Informações Estratégicas do Sistema de Vigilância em Saúde}

As informações de interesse da vigilância em saúde deverão ser coletadas e fornecidas por todos os profissionais de saúde, órgãos que integram o SUS, estabelecimentos privados de saúde e outros, devendo os órgãos do Sistema promoverem ampla disseminação dos dados analisados entre profissionais de saúde, garantindo ainda o acesso a essas informações a toda a população.

Os órgãos federais, estaduais e municipais destinados à realização de ações e serviços de saúde devem responsabilizar-se, em seus respectivos âmbitos de atuação, pela gestão do sistema de informações de interesse para a vigilância em saúde, cabendo-Ihes ainda as responsabilidades de normatizar e coordenar, em seu âmbito de ação, o fluxo das informações necessárias para a tomada de decisões para a promoção da saúde, a prevenção e o controle de riscos e doenças; consolidar e analisar, periodicamente, as informações e os dados obtidos visando fundamentar estratégias de controle de doenças e orientar o planejamento e a execução das políticas públicas de saúde no âmbito de suas competências; alimentar os sistemas nacionais de informação em saúde nos termos definidos pelo Ministério da Saúde.

Uma das fontes de informação mais importantes do Sistema de Vigilância em Saúde é a notificação compulsória. Por meio dela, os profissionais de saúde no exercício da profissão, bem como os responsáveis por estabelecimentos públicos e privados de saúde e de ensino, ficam obrigados a comunicar às autoridades sanitárias a ocorrência de casos suspeitos ou confirmados das doenças relacionados pelo Ministério da Saúde como de notificação compulsória, assim como a suspeita de ocorrência de agravos inusitados ou de situações de risco à saúde. A notificação compulsória de casos de doença e ou de agravo deve ter caráter sigiloso e a identificação do 
portador de doenças de notificação compulsória, fora do âmbito médico sanitário, somente poderá efetivar-se, em caráter excepcional, em caso de grande risco à comunidade a juízo da autoridade sanitária e com conhecimento prévio do paciente ou do seu responsável.

Recebida a notificação, ou identificado qualquer risco à saúde da população, a autoridade sanitária deve ficar obrigada a proceder à investigação epidemiológica pertinente para elucidação do diagnóstico e averiguação das fontes e formas de disseminação da doença na população sob risco, devendo exigir e promover investigações, inquéritos e outros estudos epidemiológicos junto a indivíduos e a grupos populacionais determinados, sempre que julgar oportuno, visando à proteção da saúde pública.

\section{O Sistema Nacional de Laboratórios de Saúde Pública}

Para fins de vigilância em saúde e controle de doenças e agravos à saúde, deve o Sistema Nacional de Vigilância em Saúde, por meio do Ministério da Saúde, coordenar, manter e gerir o Sistema Nacional de Laboratórios de Saúde Pública, composto pelos laboratórios públicos da União, dos Estados, do Distrito Federal e dos Municípios e pelas Redes Estaduais de Laboratórios de Saúde Pública.

Os laboratórios privados poderão participar do Sistema Nacional de Laboratórios de Saúde Pública de forma complementar, sempre que necessário e cabendo-Ihes observar as determinações exaradas pelo Ministério da Saúde.

Caberá aos laboratórios do Sistema Nacional de Laboratórios de Saúde Pública, participar da investigação etiológica de casos e eventos que impliquem risco de propagação de doenças e agravos à saúde ou que resultem de exposição a riscos ambientais ou a substâncias nocivas veiculadas pelo ar, água, alimentos ou solos contaminados e alimentar o SINVES com informações relevantes para a saúde pública, inclusive as resultantes de resultados de exames realizados em parceria com instituições internacionais.

Os laboratórios devem ainda promover e apoiar o treinamento de equipes do Sistema Nacional de Laboratórios de Saúde Pública em técnicas específicas de diagnóstico de sua área de competência, bem como promover programas de controle de qualidade e articularem-se com laboratórios internacionais de referência nas respectivas áreas de competência, buscando o aprimoramento técnico de suas equipes e dos programas nacionais de controle de qualidade laboratorial e o fortalecimento de sistemas internacionais de vigilância epidemiológica e ambiental.

Para fins de vigilância e controle de doenças e agravos à saúde, deve o Ministério da Saúde manter em funcionamento e em permanente alerta 
uma Rede Nacional de Laboratórios de Produção de Insumos Estratégicos de Saúde, composta por laboratórios públicos da União, dos Estados, do Distrito Federal e dos Municípios. Neste sentido, deve o Ministério da Saúde manter um Laboratório Nacional de Coleção de Culturas de Micro-organismos, Parasitas e de Culturas Celulares voltado ao desenvolvimento da autossuficiência em insumos estratégicos de saúde.

Em casos de suspeita de doenças transmissíveis com potencial de disseminação à coletividade, cabe à autoridade sanitária responsável no âmbito do Sistema acionar a rede de laboratórios para a rápida realização de diagnósticos in vivo e em cadáveres de pessoas suspeitas de serem portadores dessas doenças, aí incluída a coleta de amostras de tecidos em cadáveres.

A coleta de amostras, o uso de insumos e os procedimentos técnicos para exames laboratoriais, em especial nos casos de testes laboratoriais visando o diagnóstico de agravos à saúde com potencial de disseminação para a coletividade, devem ser realizados de acordo com as normas de biossegurança relativas à preservação e armazenamento de micro-organismos e parasitas isolados de amostras biológicas ou ambientais e de outros agentes e, inclusive, relativas à comercialização ou ao intercâmbio desses agentes com finalidade de pesquisa ou produção de insumos e de imunobiológicos, envolvendo instituições nacionais ou estrangeiras, excluídos aqueles geneticamente modificados.

Especial atenção também deve ser dada aos procedimentos para aquisição, comercial ou por intercâmbio, de micro-organismos e parasitas, com finalidade de controle de qualidade de testes laboratoriais e de desenvolvimento e produção de insumos e de imunobiológicos, envolvendo instituições nacionais ou estrangeiras.

\section{Das Investigações, Inquéritos e Levantamentos de Dados no âmbito do SINVES}

A organização de um Sistema Nacional de Vigilância em Saúde possibilitará que o gestor de saúde responsável identifique, com a rapidez necessária, os riscos à saúde existentes na sociedade. Sempre que isso acontencer, a autoridade sanitária, com base nas informações de que dispõe, deverá realizar a investigação pertinente para elucidação do evento e averiguação do risco potencial de disseminação da doença ou do agravo na população exposta.

Importante notar que, nestes casos, deverá ser proporcionado à autoridade sanitária o acesso às informações pertinentes para a elucidação da situação do evento pelas unidades públicas e privadas de laboratório e assistência à saúde. 
As investigações e inquéritos devem ser realizados com respeito aos direitos dos envolvidos, resguardando-se o sigilo das identidades e respeitando-se a segurança sanitária dos profissionais de saúde, agentes públicos e pacientes envolvidos.

Sempre que as informações coletadas pelo sistema assim exigirem, a autoridade sanitária responsável deverá estar pronta para adotar as medidas necessárias para o controle dos riscos identificados com a eficácia necessária para a contenção de eventual disseminação dos riscos e para evitar mortes, doenças ou outros agravos à saúde.

Dentre as medidas cabíveis para a contenção dos riscos sanitários encontram-se algumas extremamente delicadas, como o isolamento, tratamento compulsório, quarentena, cordão sanitário, entre outras. Por envolverem graves limitações aos direitos e liberdades individuais, convém a elaboração de uma legislação específica sobre o Sistema de Vigilância em Saúde que preveja, de forma aberta e transparente, e com ampla participação da comunidade, as formas e os procedimentos por meio dos quais o Estado poderá adotar tais medidas.

\section{MEDIDAS DE SAÚDE PÚBLICA DECORRENTES DA VIGILÂNCIA EM SAÚDE}

Como visto, eventualmente pode ser necessário que o Estado adote medidas de saúde pública severas para a contenção de riscos sanitários. Estas medidas, em geral, afetam a liberdade individual, razão pela qual justifica-se a elaboração de uma nova legislação que oriente os agentes públicos nestes casos e que ofereça à população garantias de que os direitos e liberdades individuais somente serão invadidos nos casos de necessidade de interesse público comprovada.

A legislação de vigilância epidemiológica brasileira, que prevê vagamente estes procedimentos, é do período da ditadura militar e data de 1975. Ou seja, é uma legislação anterior ao Sistema Único de Saúde e à própria Constituição de 1988, não contemplando diversos aspectos que fazem sentido apenas no âmbito de um Estado Democrático de Direito.

As medidas sanitárias limitativas de direitos somente poderão ser determinadas com base em evidências científicas e em análises sobre as informações estratégicas do SINVES e deverão ser limitadas no tempo e no espaço ao mínimo indispensável à promoção e à preservação da saúde pública. Ao decretar uma medida de saúde pública, é importante que a área geográfica de atuação e o período de duração das medidas sanitárias sejam delimitadas. Além disso, durante o cumprimento das medidas sanitárias restritivas da liberdade individual, o Poder Público deve responsabilizar-se pela garantia 
do tratamento médico integral, alimentação, vestuário e outros bens essenciais para que as pessoas submetidas ao regime possam viver dignamente.

A autoridade sanitária que determinar medidas sanitárias restritivas de liberdade individual deve ser obrigada a comunicar sua decisão ao órgão do Ministério Público competente ou a algum órgão de controle externo e popular, no prazo máximo de 24 horas, devendo estes órgãos de controle verificar se estão preenchidos os requisitos legais e formais para a adoção da medida e tomar as medidas judiciais que cabíveis.

Dentre as medidas de saúde pública que podem ser adotadas, destacam-se: programas nacionais de imunização obrigatória; isolamento de pessoas ou grupos; quarentena; busca ativa de contatos e observação; medidas de restrição de circulação de pessoas, bens e produtos; medidas restritivas de atividades; quimioprofilaxia, do tratamento compulsório e da realização de exames clínicos obrigatórios para fins de diagnóstico; situações excepcionais de fornecimento e disponibilidade de serviços de saúde, insumos, medicamentos, vacinas e inseticidas; sepultamento, acondicionamento e traslado de cadáveres com potencial de disseminação de doenças e agravos à saúde da coletividade controle de vetores e reservatórios etc.

Vê-se que as medidas de saúde pública podem, com efeito, invadir a esfera da liberdade individual de forma bastante agressiva. No entanto, esta invasão, no âmbito do Estado Democrático de Direito, será sempre permitida quando feita nos termos da lei e em defesa do interesse público, no caso, a proteção da saúde pública contra riscos à saúde identificados na sociedade. Trata-se, como se pode perceber, de assunto delicado que somente um amplo debate social pode oferecer um tratamento adequado, definindo-se, por meio de lei, quais são as regras e os procedimentos que o Estado deve adotar nos casos de riscos à saúde pública. Este tema é ainda mais importante quando verificamos a possibilidade de existência de emergências em saúde pública que podem exigir das autoridades sanitárias ação imediata e eficaz. Os casos recentes de gripe aviária, gripe suína ou outros vírus letais nos mostram que a adoção de regras jurídicas democráticas sobre como pode e deve o Estado agir nestes casos é fundamental para que se ofereça à população uma adequada proteção da saúde.

\section{DA EMERGÊNCIA EM SAÚDE PÚBLICA DE RELEVÂNCIA NACIONAL}

Sempre que, em decorrência dos resultados obtidos mediante análises de informações em saúde, as autoridades sanitárias responsáveis entenderem configurar-se uma situação de emergência em saúde pública de relevância nacional, deve-se adotar procedimentos padrões que orientem a atuação do Estado. Considera-se uma emergência de saúde pública de relevância 
nacional o evento de saúde pública que implique risco para a saúde pública nacional, independente da sua origem, natureza ou fonte, e que atenda aos seguintes requisitos: apresente magnitude, potencial de disseminação ou propagação, gravidade e relevância social e econômica; apresente padrões epidemiológicos não habituais, tais como o aumento da incidência, da gravidade, da letalidade ou das sequelas; esteja relacionada a novo agente etiológico, nova doença ou a agente químico ou físico ou a doença já conhecida, mas que apresente modificações de seu comportamento que propicie condições de maior e mais rápida disseminação ou propagação e/ou gravidade.

A avaliação dos critérios deverá ser apropriada para cada evento, considerando o contexto da população e território acometido, bem como o período de ocorrência. Devem também ser consideradas emergências de saúde pública de relevância nacional aquelas decorrentes da aplicação dos acordos internacionais nos quais o Brasil seja parte, especialmente os firmados no âmbito da Organização Mundial de Saúde - OMS.

Sempre que existir uma situação de Emergência de Saúde Pública no país, deve-se criar um mecanismo de gestão por meio do qual o Ministro de Estado da Saúde, ouvido o Conselho Nacional de Saúde, oficie o Presidente da República recomendando a expedição de um Decreto de Estado de Emergência de Saúde Pública Nacional. Este decreto conterá, necessariamente: caracterização e fundamentação do Estado de Emergência de Saúde Pública declarado; circunscrição territorial do risco à saúde identificado e das áreas de atuação intensiva dos Poderes do Estado para a contenção do risco; o nível de emergência; a definição do tempo de duração da Emergência; definição das medidas de saúde pública a serem adotadas e dos órgãos competentes para sua adoção, durante o período de tempo de vigência da Emergência.

Juntamente com a declaração de Estado de Emergência, o Presidente da República deve criar um Comitê Executivo de Emergência, coordenado pelo Ministro de Estado da Saúde e composto pelos órgãos técnicos competentes e aptos para enfrentarem a emergência. A declaração de Estado de Emergência de Saúde Pública poderá abranger todo o território nacional, ou parte dele, consoante o âmbito geográfico dos seus fatores determinantes, na medida do necessário para manter ou restabelecer a normalidade.

Por se tratar de medida excepcional, a declaração de Estado de Emergência de Saúde Pública deve ter sua duração limitada ao tempo necessário para a salvaguarda dos direitos e interesses que visa proteger. Na hipótese de não ser possível ouvir o Conselho Nacional de Saúde antes da declaração de Estado de Emergência de Saúde Pública, deve-se dar ao Ministro da Saúde a possibilidade de convocar reunião extraordinária do CNS, que deverá realizar-se no período mais breve possível. 
Cessadas as circunstâncias que tiverem determinado a declaração de Emergência de Saúde Pública, caberá ao Presidente da República expedir Decreto de revogação do Estado de Emergência de Saúde Pública. Todas as alterações efetuadas no Decreto que declara o Estado de Emergência de Saúde Pública deverão ser imediatamente analisadas pelo Comitê Executivo de Emergência, que adotará, se for o caso, as providências necessárias.

Uma vez declarado o Estado de Emergência de Saúde Pública, deve a União, por meio do Ministério da Saúde, coordenar, nacionalmente, a execução das ações necessárias para o controle da situação que deu origem à declaração de Emergência. Para tanto, deverá articular os órgãos federais para que atuem de forma coordenada para o controle da situação que deu origem ao Estado de Emergência, notadamente a Defesa Civil, o Ministério da Defesa e os demais órgãos e agências que possam cooperar. A articulação deverá abranger ainda os Estados, o Distrito Federal e os Municípios, para que promovam as ações conjuntas necessárias de contenção e controle do risco.

Além disso, durante a vigência da Emergência em Saúde Pública, deve a União estar apta a: requisitar, se necessário, apoio operacional dos órgãos federais, estaduais e municipais, inclusive a disponibilidade de recursos físicos e humanos; coordenar as ações governamentais de todos os níveis da Federação para que fiquem assegurados os serviços públicos essenciais durante o período de Emergência; organizar as ações de forma a proteger os servidores públicos e os voluntários que cooperarem nas ações de controle e contenção da situação que deu origem à Emergência; utilizar as verbas orçamentárias necessárias para a execução das ações de contenção e controle do risco à saúde gerador do Estado de Emergência; manter a população informada sobre o Estado de Emergência de Saúde Pública declarado, as ações que estão sendo tomadas pelo Poder Público e as medidas que devem ser tomadas pela população para a redução dos riscos.

Declarado o Estado de Emergência de Saúde Pública, as pessoas físicas e jurídicas, de direito público e privado, deverão sujeitar-se às medidas determinadas pelo Decreto Presidencial e, posteriormente, pelo Ministério da Saúde, admitindo-se a utilização de todas as medidas de saúde previstas, tais como isolamento, quarentena, tratamento compulsório e outras.

Parece evidente, assim, que a Declaração de Emergência de Saúde Pública caracteriza perigo público, aplicando-se o disposto no art. 5ํ, XXV da Constituição da República, justificando medidas excepcionais em prol da segurança sanitária nacional.

\section{CONSIDERAÇÕES FINAIS}

O reconhecimento da saúde como direito de todos e dever do Estado pela Constituição Federal gerou uma série de consequências jurídicas que devem ser encaradas com a atenção e enfrentadas com coragem e amplo 
debate público. Ao obrigar o Estado a adotar políticas públicas que visem à redução do risco de doenças e outros agravos à saúde, a Constituição brasileira exige a organização de uma rede de serviços públicos capaz de identificar os agravos existentes em nossa sociedade e adotar as medidas de saúde pública necessárias para seu controle ou eliminação. Este dever, inscrito no âmbito do princípio da segurança sanitária, pode ser resumido no dever de vigilância em saúde do Estado brasileiro.

Assim, sem diminuir a importância das especializações no âmbito da vigilância em saúde, bem como a importância das atuações de todos os entes federativos nesta atividade estatal, é preciso também reconhecer a importância de que as vigilâncias se integrem e articulem de forma a permitir ao gestor de saúde uma visão mais global e integral do risco à saúde, possibilitando sua identificação rápida e eficaz. É necessário, portanto, a criação e organização de um Sistema Nacional de Vigilância em Saúde que articule as diferentes vigilâncias da área de saúde entre si, inserindo as vigilâncias sanitária, epidemiológica e ambiental no mesmo contexto jurídico e administrativo. Tal sistema deve ser responsável, também, por integrar e articular as atividades de vigilância em saúde com as atividades de atenção à saúde e também com as atividades desenvolvidas por outros órgãos da Administração Pública, como os órgãos ambientais e os que lidam com as questões agrícolas e de comércio e indústria.

Um Sistema Nacional de Vigilância em Saúde, dotado de instrumentos eficazes de gestão, como um sistema de informações e análises estratégicas em saúde, os inquéritos de vigilância em saúde, a notificação compulsória, dentre outros, será capaz de oferecer à população as garantias de proteção à saúde requeridas pela Constituição Federal. Ele também possibilitará a adoção de medidas de saúde pública coordenadas e eficazes capazes de enfrentar com precisão e eficácia os riscos à saúde que venham a ser encontrados, em um ambiente de respeito aos princípios democráticos e ao Estado de Direito. Finalmente, um Sistema Nacional de Vigilância em Saúde poderá organizar a forma como o Estado do Brasil irá agir nos casos de emergência em saúde pública que coloquem em risco a segurança sanitária nacional.

Estas linhas são uma contribuição inicial para o debate sobre o tema. Espera-se que, com o amadurecer de nossa vivência democrática, a discussão acima colocada gere propostas concretas e possibilite o avanço jurídico e institucional do Estado brasileiro para o enfrentamento dos relevantes desafios colocados para a vigilância em saúde no mundo moderno.

\section{REFERÊNCIAS BIBLIOGRÁFICAS}

ALBERT, M. Capitalisme contre capitalisme. Paris: Seuil, 1991.

BONAVIDES, Paulo. Curso de direito constitucional. 9. ed. São Paulo: MaIheiros, 2000. 
COMPARATO, Fabio Konder. A afirmação histórica dos direitos humanos. 1 ed., São Paulo: Saraiva, 1999.

DUCLOS, D. Puissance et faiblesse du concept de risque. L'Année Sociologique, v. 46, n. 2, p. 309-337, 1996.

DURAND, Christelle. A segurança sanitária num mundo global: aspectos legais e o sistema de segurança sanitária na França. Revista de Direito Sanitário, São Paulo, v. 2, n. 1, mar. 2001.

EWALD, François. Philosophie de la précaution. L'Année Sociologique, v. 46, n. 2, p. 382-307, 1996.

HABERMAS, J. Droit et démocratie: entre faits et normes. Paris: Gallimar, 1996.

LAFER, Celso. A reconstrução histórica dos direitos humanos. 2. ed. São Paulo: Companhia das Letras, 1998.

NIKEN, Pedro. El concepto de derechos humanos. San José de Costa Rica: Instituto Interamericano de Derechos Humanos, 1994. (Série Estudios de Derechos Humanos, t. 1)

ROSANVALON, P. La nouvelle question sociale. Paris: Seuil, 1995.

TRINDADE, Antonio Augusto Cançado. Tratado de Direito Internacional dos Direitos Humanos, Volumes I e II, Sergio Antonio Fabris Editor, Porto Alegre, Brasil, 1997.

WORMS, F. Risques communs, protection publique et sentiment de justice. L’Année Sociologique, v. 46, n. 2, p. 287-307, 1996. 